\title{
The Efficiency Of Using Incinerated Organic Waste As An Alternative Aggregate For Concrete
}

\author{
Hossam. A. Elaqra*,*******, Saddam H. Qarmout**, Jehad T. Hamad ${ }^{* * *}$, Eyad A. Hadad ${ }^{* * * *}$ and Fahad K. \\ Alqahtani $^{* * * * *}$ \\ *Associate Professor, Civil Engineering Department, University of Palestine (UP), Gaza, Palestine, (French) \\ ***Engineer, Civil Engineering Department, Islamic University of Gaza (IUG), Gaza, Palestine, (Palestinian) \\ ${ }^{* * *}$ Assistant Professor, Civil Engineering Department, Islamic University of Gaza (IUG), Gaza, Palestine, (Palestinian) \\ ${ }^{* * * *}$ Assistant Professor, Civil Engineering Department, University of Palestine (UP), Gaza, Palestine, (Palestinian) \\ ${ }^{* * * * * *}$ Assitant Professor, Civil Engineering Department, College of Engineering, King Saud University (KSU), P.O.Box 800, Riyadh 11421, \\ Saudi Arabia, (Saudi Arabian) \\ ********Corresponding Author: helaqra@gmail.com
}

Submitted: 29-09-2020

Revised: $15-07-2021$

Accepted: 28-07-2021

\begin{abstract}
With the growth of the global population, two major problems have emerged. Firstly, a significant amount of domestic and industrial waste is discarded and placed in landfills. Secondly, there is a necessity for more construction and building materials. This research discusses the use of alternative green resources for construction materials taken from recycled organic waste, which represents more than $60 \%$ of the total waste generated by humans. Results showed that, after incineration at $750{ }^{\circ} \mathrm{C}$, the reminder represented less than $15 \%$ of the original mass of the waste. The waste was separated into five groups: bottom ash (BA) powder, this part represented $5 \%$ of the reminder after incineration (for replacing cement); sand; and fine, medium and coarse aggregates. The powder underwent a pozzolanic reaction and the optimum replacement was $10 \%$ for the powder, $30 \%$ for the sand, and $10 \%$ for the fine, medium, and coarse aggregates. A higher compressive strength was applied to the medium aggregate replacement and a lower one for the fine aggregate. In general, BA can be used as an aggregate replacement as the powder undergoes a pozzolanic reaction and can used as a replacement for cement.
\end{abstract}

Key Words: Concrete, Municipal waste, Bottom ash, Mechanical properties, Relative Activation index.

\section{INTRODUCTION}

Sustainability, durability, cost-effectiveness, straightforward casting, robustness and other advantages affirm that concrete is the most abundant construction material globally (IEA, 2018); although, $\mathrm{CO}_{2}$ emissions from the cement industry place a moral restriction on its use, as cement factories produce $7 \%$ of the total $\mathrm{CO}_{2}$ emissions (Chen et al., 2010). Additionally, the effort attributed to the reduction of waste, the limitations of natural resources and the employment of more sustainable concrete for construction issues have forced researchers to obtain an alternative green material for inexpensive, eco-friendly and green concrete with structural benefits. Bottom ash (BA), which is derived from the incineration of organic waste, is an industrial by-product originating from thermal power plants. It presents some ecological benefits as an alternative source for cement (Whittaker et al., 2009; Abdullah et al., 2017); aggregates (Elaqra et al., 2019); road pavement (Aggarwal and Siddique, 2014); and glass and ceramics (Tang et al., 2014).

According to the World Bank Group (2016), 2.01 billion tons of solid waste were generated by the worlds' cities, which is equal to 0.74 kilograms per person per day (Kaza et al., 2018). This amount will reach 3.40 billion tons by 2050 , with an expected increase of $70 \%$. Table 1 depicts the global waste distribution. 
Table 1. Distribution of waste in the world (Kaza et al., 2018)

\begin{tabular}{|l|l|l|l|l|l|}
\hline Type & Organic & Paper and cardboard & Plastic & Metal & Glass \\
\hline Percentage (\%) & $43 \%$ & $17 \%$ & $12 \%$ & $4 \%$ & $5 \%$ \\
\hline
\end{tabular}

There are concerns about the Gaza Strip, which is a closed area (around $362 \mathrm{~m}^{2}$ ), where the poulation has increased dramatically, a huge amount of solid waste has resulted without any, as shown in Table 2.

Table 2. The amount of waste in the Gaza Strip (ton/day) and predicted amounts in 2030 and 2040 (Maqadmh et al., 2015)

\begin{tabular}{|l|l|l|l|l|l|l|}
\hline Year & 2013 & 2014 & 2015 & 2020 & 2030 & 2040 \\
\hline Total amount (ton/day) & 1753 & 1813 & 1855 & 2097 & 2668 & 3023 \\
\hline
\end{tabular}

Table 3 depicts the type of waste in the Gaza Strip and the distribution demonstrates that organic waste represents the majority of the waste.

Table 3. Distribution of waste in the Gaza Strip according to the type of waste (Abu El qomboz and Habil, 2013)

\begin{tabular}{|l|l|l|l|l|l|l|l|l|}
\hline Waste & Organic & Sand & Paper & Plastic & Glass & Metal & Textile & Others \\
\hline Percentile (\%) & $67 \%$ & $10 \%$ & $8 \%$ & $7 \%$ & $2 \%$ & $2 \%$ & $2 \%$ & $2 \%$ \\
\hline
\end{tabular}

One lightweight green aggregate compared with cement or natural aggregates is bottom ash, as its density is governed by the origin of the waste. Organic, paper, plastic and textile wastes tend to maintain a mass below 1 $\mathrm{g} / \mathrm{cm} .{ }^{3}$ Moreover, metal, glass and other heavy materials have a tendency to increase the density of BA (Siddique, 2010; Huang et al., 2020). Another parameter that determines the type of replacement by BA is its size, where it varies according to the type of incinerator and the origin of the waste (Lynn et al., 2016). The BA powder (smaller than $75 \mu \mathrm{m}$ ) generally represents approximately 3\% of the total waste (Alhassan and Tanko, 2012).

The use of BA as cement is governed by its chemical composition because BA can have pozzolanic properties due to the presence of calcium aluminodisilicate $\left(\mathrm{CAS}_{2}\right)$ and aluminosilicate (AS) (Rémond et al., 2002). Table 4 presents the chemical composition of ash in the existing literature. Its major composition is the same as cement; nonetheless, the amount of $\mathrm{CaO}$ is extremely small compared to cement, while the amount of $\mathrm{SiO}_{2}$ is higher. The presence of chloride is considered a cement accelerator, the optimum is located at $10 \%$ and the BA undergoes a pozzolanic reaction especially during a long curing time (Rémond et al., 2002).

Table 4. Chemical composition of BA compared to cement

\begin{tabular}{|l|l|l|l|l|l|l|l|l|l|}
\hline & $\mathrm{CaO}$ & $\mathrm{SiO}_{2}$ & $\mathrm{Al}_{2} \mathrm{O}_{3}$ & $\mathrm{Fe}_{2} \mathrm{O}_{3}$ & $\mathrm{SO}_{3}$ & $\mathrm{MgO}$ & $\mathrm{K}_{2} \mathrm{O}$ & $\mathrm{Na}_{2} \mathrm{O}$ & $\mathrm{C} 1$ \\
\hline Elaqra and Rustom (2018) Cement & 66.69 & 18.84 & 6.3 & 3.72 & 2.66 & 0.61 & 0.5 & 0 & 0 \\
\hline Rémond et al. (2002) BA & 16.4 & 27.2 & 11.7 & 1.8 & 3 & 2.5 & 5.8 & 5.9 & 7.2 \\
\hline Keppert (2012) BA & 19.4 & 33.5 & 15.8 & 8.4 & 9.3 & 2 & 1.9 & 3.6 & 1.1 \\
\hline Tang et al. (2014) BA & 21.9 & 39.3 & 10.1 & 12.7 & 3.7 & 0 & 0 & 0 & 0.8 \\
\hline
\end{tabular}


Throughout the mixing, the use of BA decreases workability, because it demands more water due to its higher water absorption in comparison to natural aggregates (Li et al., 2012; Aggarwal and Siddique, 2014). In general, as the BA replacement increases, the compressive strength attains the optimum and then it decreases; meanwhile, the value is still less than the control.

Used as a sand replacement by up to $15 \%$, the optimum is located at $5 \%$; the compressive strength is stable after 28 days and the control increases by $20 \%$. This occurs due to the large amount of sulfate and chloride, which has a negative effect on the concrete (Keppert, 2012). Van der Wegen et al. (2013) replaced the coarse aggregate with $20 \%$ of BA and the results demonstrated that the compressive strength was $84 \%$ of the control at 28 days and $90 \%$ at 90 days. In contrast, Abbà et al. (2017) tried a 50\% replacement of the coarse aggregate with BA and an increase of the w/c in order to have the same slump. The results revealed an increase in the compressive strength by up to $102 \%$ after 28 days. A replacement of up to $50 \%$ of the fine aggregate by BA with the same w/c demonstrated a lower slump and compressive strength. At 28 days, the compressive strength for $10 \%$ BA had $96 \%$ of the control, while $50 \%$ had $43 \%$ of the control (An et al., 2017).

The aim of this research is to use BA obtained from the incineration of organic waste collected from municipal waste. It will be air dried, oven dried, and then incinerated at $750{ }^{\circ} \mathrm{C}$, in order to obtain the BA for the replacement of cement, sand, and fine, medium and coarse aggregates. It is noted that the incineration process was done in the laboratory. Samples will be prepared with different amounts of replacement in order to evaluate them mechanically using compression tests. The activation index will be used to examine the pozzolanic activity of the powder.

\section{EXPERIMENTAL AND TESTING PROGRAM}

The experimental program is composed of the following steps:

Step 1. Obtain an alternative aggregate from domestic waste by applying the following steps:

1. Collect the solid municipal waste

2. Separate the organic component from the solid waste

3. Air dry the samples at $35^{\circ} \mathrm{C}$

4. Oven dry the sample at $105^{\circ} \mathrm{C}$

5. Burn the dried waste at $750{ }^{\circ} \mathrm{C}$

6. Separate the alternative aggregate into four sizes (smaller than $75 \mu \mathrm{m}$ powder, sand smaller than $600 \mu \mathrm{m}$, fine and coarse aggregates)

Step 2. Chemical analysis andinvitsigate the physical properties of the alternative aggregate.

Step 3. Mix concrete specimens according to the replacement of the natural sand, aggregate and cement, and conduct curing until test data is obtained.

Step 4. Density calculation and mechanical testing (compressive test) in order to evaluate the effect of the replacement. 


\section{MATERIALS}

\section{Cement}

Local CEMII 42.5 N, SVL was used in this study. Table 8 shows the chemical composition of the cement used.

\section{Aggregates}

Natural sand and aggregate were used in this study from a local crushing site. Figure 1 depicts the particle size distribution of the natural sand and the aggregate according to the ASTM C136/C136M-14. The local sand was smaller than $0.6 \mathrm{~mm}$, and the fine aggregate size was between $0.6 \mathrm{~mm}$ and $10 \mathrm{~mm}$. The medium aggregate was between $10 \mathrm{~mm}$ and $20 \mathrm{~mm}$ in size and the coarse aggregate was larger than $20 \mathrm{~mm}$. The curve depicts a positive grade distribution, where the cumulative curve is located between the maximum and minimum percentage.

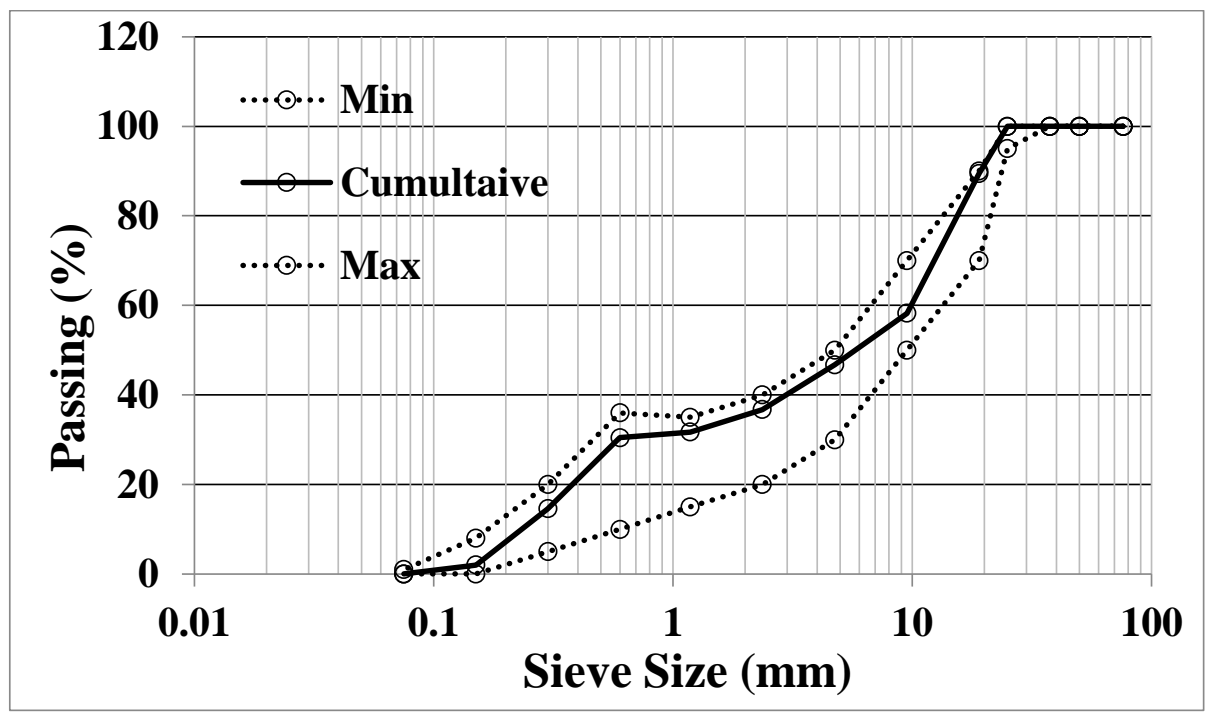

Figure 1. Cumulative particles' size distribution of the natural aggregates

\section{Alternative green aggregates}

Municipal waste $(200 \mathrm{~kg})$ was collected from more than one site in order to have a representative sample from the Gaza Strip waste. After separation, the organic waste weighed approximately $160 \mathrm{~kg}$, which represents $80 \%$ of the total waste. It is worth noting that the organic waste was composed essentially from vegetables and some bone. Thereafter, the sample was placed in an open area at a temperature between 32 and $35^{\circ} \mathrm{C}$. After five days, the sample weighed approximately $80 \mathrm{~kg}$ and the following step entailed placing the sample in the oven at $105{ }^{\circ} \mathrm{C}$ for $24 \mathrm{~h}$ in order to remove the free water. The sample was reduced to $25 \mathrm{~kg}$ and the final step was burning the $25 \mathrm{~kg}$ of waste at $750{ }^{\circ} \mathrm{C}$ for $2 \mathrm{~h}$ to ensure the elimination of the organic component in the BA. The remaining ash after burning weighed $7.3 \mathrm{~kg}$, which represents approximately $4.6 \%$ of the total amount of organic waste (see Fig. 2).

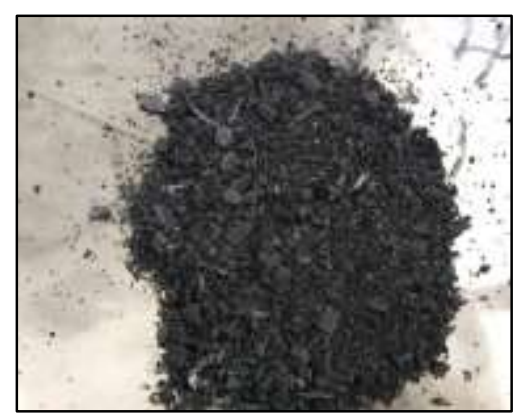

Figure 2. Image of remaining ash after burning at $750{ }^{\circ} \mathrm{C}$ 
Figure 3 shows the mass loss of the organic waste after each step. At $105{ }^{\circ} \mathrm{C}$, the free water departs from the sample and it represents more than $80 \%$ of the organic structure, which comes from the nature of the waste. The carbonation and elimination of the organic components occur at $750{ }^{\circ} \mathrm{C}$.

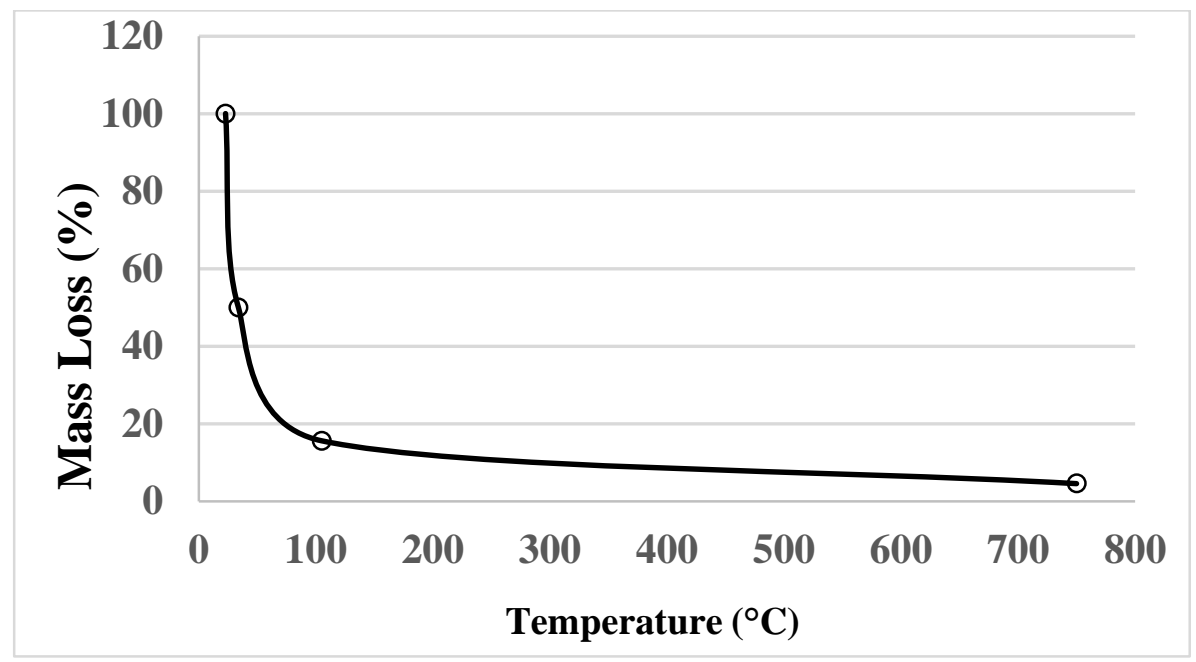

Figure 3. Mass loss after each treatment of the organic waste

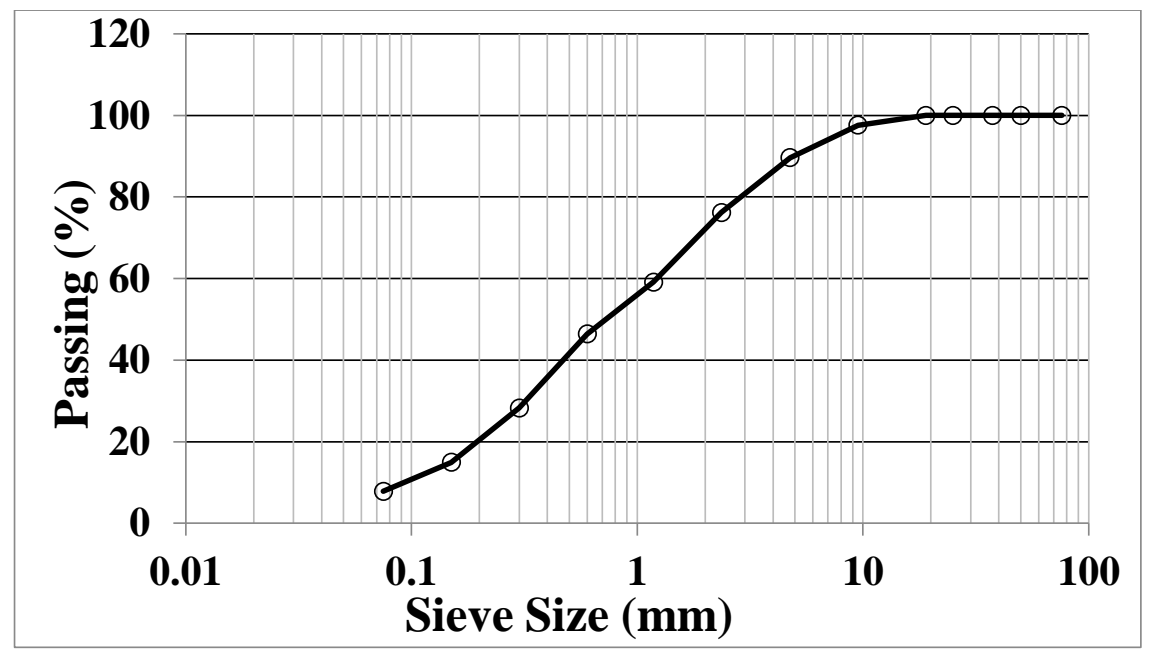

Figure 4. Particle size distribution of BA

Figure 4 depicts the cumulative particle size distribution of the BA according to the ASTM $\mathrm{C} 136 / \mathrm{C} 136 \mathrm{M}-14$. The fine aggregate represents approximately $85 \%$ of the BA, originating from the nature of the domestic waste.

Table 5 hows the value of the density and the absorption (according to ASTM C642) of each material used within this study.

Table 5. The properties of the materials used

\begin{tabular}{|l|l|l|}
\hline & Density $\left(\mathrm{g} / \mathrm{cm}^{3}\right)$ & Absorption (\%) \\
\hline Cement & 3.15 & \\
\hline Sand & 2.67 & $0.03 \%$ \\
\hline Natural aggregate & 2.7 & $2.7 \%$ \\
\hline
\end{tabular}




\begin{tabular}{|l|l|l|}
\hline Bottom ash & 0.8 & $42.5 \%$ \\
\hline
\end{tabular}

\section{PROPORTIONS}

\section{Concrete}

Cubic samples with the dimensions of $100 * 100 * 100 \mathrm{~mm}$ were cast according to the investigation variables. Mixes were prepared with BA as cement (10\% and 20\%), sand (15\%,30\% and 50\%), fine (FA), medium (MA) and coarse aggregate (CA) replacements with a cement to water ratio equal to 0.53 .

Samples were tested at different ages, namely 7 and 28 days in order to evaluate the mechanical behavior. Mixing of the sample was conducted according to the ASTM C192/C192M-16a.

Tables 6-7 reveal the mix proportion used within this study, and the percentage of the replacement of each component. The amount of water to cement ratio was adjusted according to the mix's workability or to a fixed percentage. Two control mixes were used, the first with a water to cement ratio equal to 0.53 and the second according to the percentage of $w / c$ of the mix with an aggregate replacement ( $w / c=0.63,0.74$ and 0.84 ).

\section{Mixing concrete}

The two-stage method was used for mixing the concrete. This method was proposed by Tam et al. (2005) and was supported by subsequent studies (Tam and Tam, 2006; Tam et al, 2007; Tam and Tam, 2007; Elaqra, 2014, 2015, 2019; Elaqra et al., 2019a). This method involves mixing part of the water with the aggregate, adding all the cement, and the final step is mixing in the remaining water. The aim of this method is to facilitate the penetration of the cement paste into the poro-aggregate (aggregate with higher porosity resembling a crushed or lightweight texture). In this research, putting in the water first will help the adhesion of the cement particles onto the surface of the aggregate. When the remaining water is added, the penetration of the cement paste will occur, providing the aggregate with more strength. It should be noted that mixes with a high replacement had a higher water to cement ratio, which came from the higher water absorption of the BA.

Table 6. Concrete composition

\begin{tabular}{|c|c|c|c|c|c|c|}
\hline & $\begin{array}{c}\text { Cement } \\
\left(\mathrm{kg} / \mathrm{m}^{3}\right)\end{array}$ & $\begin{array}{c}\text { Sand } \\
\left(\mathrm{kg} / \mathrm{m}^{3}\right)\end{array}$ & $\begin{array}{c}\text { Aggregate } \\
\left(\mathrm{kg} / \mathrm{m}^{3}\right)\end{array}$ & $\begin{array}{c}\text { BA } \\
\left(\mathrm{kg} / \mathrm{m}^{3}\right)\end{array}$ & $\begin{array}{c}\text { Water } \\
\left(\mathrm{kg} / \mathrm{m}^{3}\right)\end{array}$ & w/c ratio \\
\hline Control mix & 330 & 660 & 1170 & 0 & 175 & 0.53 \\
\hline Cement (10\%) & 297 & 660 & 1170 & 33 & 175 & 0.53 \\
\hline Cement (20\%) & 264 & 660 & 1170 & 66 & 208 & 0.63 \\
\hline Sand (15\%) & 330 & 561 & 1170 & 99 & 208 & 0.63 \\
\hline Sand (30\%) & 330 & 462 & 1170 & 198 & 244.2 & 0.74 \\
\hline Sand (50\%) & 330 & 330 & 1170 & 330 & 277.2 & 0.84 \\
\hline
\end{tabular}


Table 7. Concrete composition

\begin{tabular}{|l|c|c|c|c|c|c|c|c|}
\hline & $\begin{array}{c}\text { Cement } \\
\left(\mathrm{kg} / \mathrm{m}^{3}\right)\end{array}$ & $\begin{array}{l}\text { Sand } \\
\left(\mathrm{kg} / \mathrm{m}^{3}\right)\end{array}$ & $\begin{array}{l}\text { CA } \\
\left(\mathrm{kg} / \mathrm{m}^{3}\right)\end{array}$ & $\begin{array}{l}\text { MA } \\
\left(\mathrm{kg} / \mathrm{m}^{3}\right)\end{array}$ & $\begin{array}{c}\text { FA } \\
\left(\mathrm{kg} / \mathrm{m}^{3}\right)\end{array}$ & $\begin{array}{l}\text { BA } \\
\left(\mathrm{kg} / \mathrm{m}^{3}\right)\end{array}$ & $\begin{array}{l}\text { Water } \\
\left.\left(\mathrm{kg} / \mathrm{m}^{3}\right)\right)\end{array}$ & w/c \\
\hline Control & 330 & 660 & 660 & 250 & 350 & 0 & 175 & 0.53 \\
\hline CA (10\%) & 330 & 660 & 594 & 250 & 350 & 66 & 175 & 0.53 \\
\hline MA (10\%) & 330 & 660 & 660 & 225 & 350 & 25 & 175 & 0.53 \\
\hline FA (10\%) & 330 & 660 & 660 & 250 & 315 & 35 & 175 & 0.53 \\
\hline
\end{tabular}

\section{TESTING PROCEDURE}

\section{Chemical analysis}

The objective of this test is to determine the chemical composition of the BA using flame atomic absorption spectrophotometry according to the ASTM D4691-17. In contrast, the cement composition was determined by X-Ray Fluorescence (XRF) as affirmed by Elaqra and Rustom (2018).

\section{Density}

According to ASTM C642-13, the density was calculated using Eq. 1:

$$
\rho=\frac{M}{V}
$$

\section{MECHANICAL TESTING}

\section{Compressive strength tests}

The concrete mixes were subjected to a compression test according to ASTM C39/C39M-18 at 7 and 28 days. At least three tests were conducted for each point on the figures, where the standard deviation was generally less than $3 \%$.

\section{Relative Activation Index (RAI)}

$\mathrm{Pu}$ (2004) proposed Eq. 2 to study the reactivity of any replacement of cement or addition to cement:

$$
\mathrm{RAI}=1-\frac{\text { Compressive Strength of Control mix } * \text { GP percentage }}{\text { Compressive Strength of GP mix } * 100}
$$

\section{RESULTS AND DISCUSSION}

\section{Chemical analysis and XRF}

Table 8 presents the chemical composition of the cement and the BA powder. The BA powder is composed from the same oxide as the cement, which provides the rationale for cement replacement. 
Table 8. Chemical composition of cement and BA

\begin{tabular}{|l|l|l|l|l|l|l|l|l|l|l|}
\hline & $\mathrm{CaO}$ & $\mathrm{SiO}_{2}$ & $\mathrm{Al}_{2} \mathrm{O}_{3}$ & $\mathrm{Fe}_{2} \mathrm{O}_{3}$ & $\mathrm{SO}_{3}$ & $\mathrm{MgO}$ & $\mathrm{K}_{2} \mathrm{O}$ & $\mathrm{P}_{2} \mathrm{O}_{5}$ & $\mathrm{Na}_{2} \mathrm{O}$ & $\mathrm{C} 1$ \\
\hline CEMII & 66.69 & 18.84 & 6.3 & 3.72 & 2.66 & 0.61 & 0.5 & 0.70 & 0 & 0 \\
\hline BA & 56.2 & 1.9 & 0.78 & 7.4 & 0 & 12.2 & 23.8 & 0 & 10 & 24.9 \\
\hline
\end{tabular}

\section{Density}

Table 9 presents the results of the density according to the variation of the mixes and the age. The variation of the density is related to the initial amount of each ingredient in the mix. As the replacement is carried out with a lighter aggregate, the mix has a lower density. In contrast, as the aggregates become larger (such as CA), the possibility of the cement paste penetrating into the porosity becomes easier. This affects the mechanical behavior of the BA aggregate when it replaces larger aggregates in comparison to smaller ones. The use of the two-stage mixing method is the reason for this and as a result, the larger aggregates have better mechanical properties than the smaller aggregates.

Table 9. Density of the mixtures

\begin{tabular}{|c|c|c|c|}
\hline Mix & $\mathrm{w} / \mathrm{c}$ & $\begin{array}{l}7 \text { days } \\
\mathrm{g} / \mathrm{cm}^{3}\end{array}$ & $\begin{array}{c}28 \text { days } \\
\mathrm{g} / \mathrm{cm}^{3}\end{array}$ \\
\hline Control & 0.53 & 2.5 & 2.54 \\
\hline Control & 0.63 & 2.45 & 2.5 \\
\hline Control & 0.74 & 2.41 & 2.445 \\
\hline Control & 0.84 & 2.35 & 2.395 \\
\hline $10 \%$ Cement & 0.53 & 2.47 & 2.515 \\
\hline $20 \%$ Cement & 0.63 & 2.405 & 2.475 \\
\hline $15 \%$ Sand & 0.63 & 2.41 & 2.465 \\
\hline $30 \%$ Sand & 0.74 & 2.345 & 2.365 \\
\hline $50 \%$ Sand & 0.84 & 2.2 & 2.3 \\
\hline $10 \% \mathrm{FA}$ & 0.53 & 2.485 & 2.5 \\
\hline $10 \% \mathrm{MA}$ & 0.53 & 2.52 & 2.54 \\
\hline $10 \% \mathrm{CA}$ & 0.53 & 2.482 & 2.52 \\
\hline
\end{tabular}




\section{HARDENED PROPERTIES}

\section{Mechanical properties}

\section{Cement replacement}

Figure 5 shows the compressive strength as a function of age and BA as the cement replacement (10\% and $20 \%)$. As the figure shows, the more there is of the replacement, the less the compression strength. Moreover, the $20 \%$ BA mix requires more water in order to have the same workability as the control mix. The effect of the excessive amount of water in comparison to the control and the $10 \% \mathrm{BA}$ mix is added to the effect of the cement replacement by a material less reactive and binding. This plays a determining role in the $20 \%$ decrease of the compressive strength.

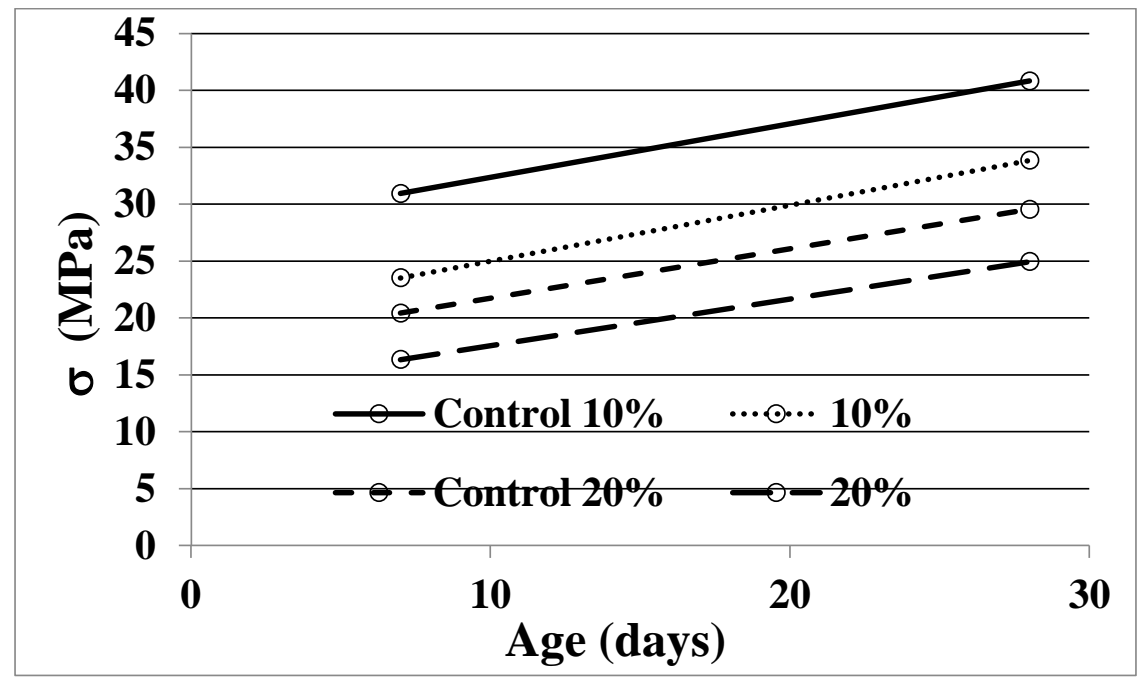

Figure 5. The compressive strength of concrete as a function of age and BA as cement replacement

The calculation of the normalized compressive strength provides a more comprehensive understanding of the effect of the value changes. Figure 6 shows the result of the $10 \%$ BA mix calculated in comparison to the control, the $20 \%$ BA mix is calculated in reference to its control (20\% control), and the $20 \%$ BA mix based on its control is calculated in reference to the $10 \%$ BA mix control.

As stated in section 1926.752(a) of the US Department of Labor, Occupational Safety and Health Administration, "an appropriate ASTM standard test method of field-cured samples, either 75 percent of the intended minimum compressive design strength or sufficient strength to support the loads imposed during steel erection is needed.

At 28 days, the normalized compressive strength demonstrated that all mixes satisfied the requirement of strength, which exceeds $75 \%$ of the control. In contrast, all the mixes had a higher normalized stress, which comes from the activation of the BA as a binder. 


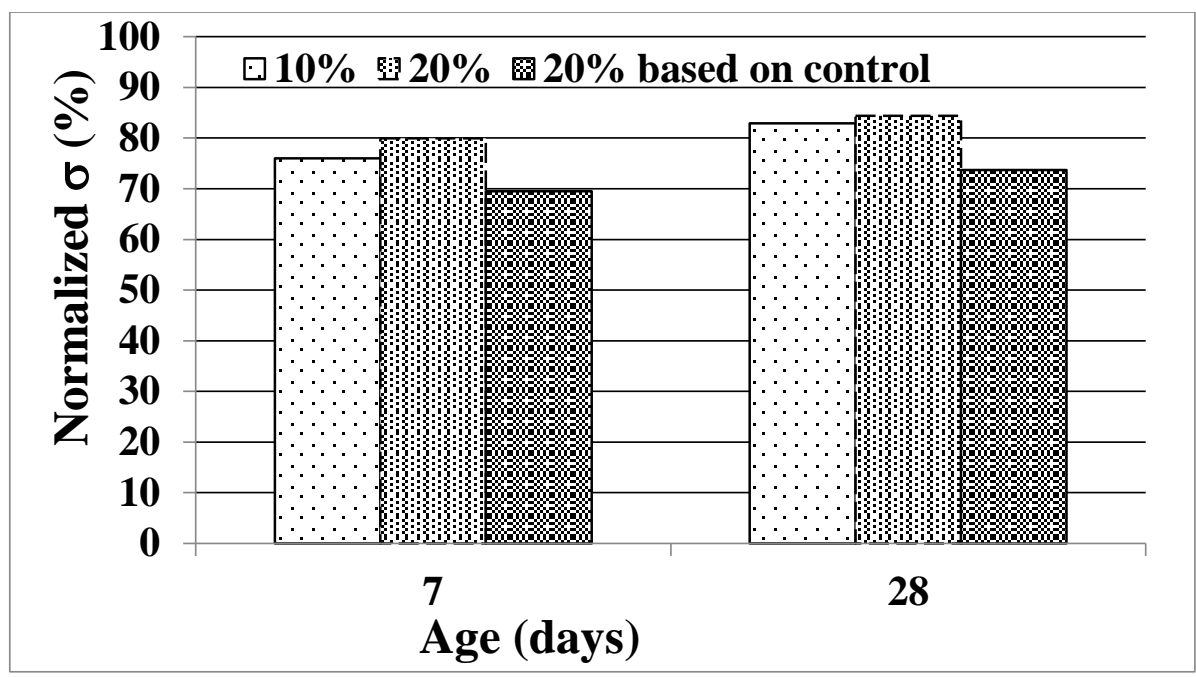

Figure 6. Relative compressive strength of concrete as a function of age and BA cement replacement

Figure 7 presents the calculation of the relative index activation as a function of age and replacement. Only the $20 \%$ BA mix based on the control of $20 \%$ BA was the mix with the positive index, which indicates that a higher w/c ratio activates the BA. The RAI becomes higher at 28 days, which indicates a pozzolanic reaction.

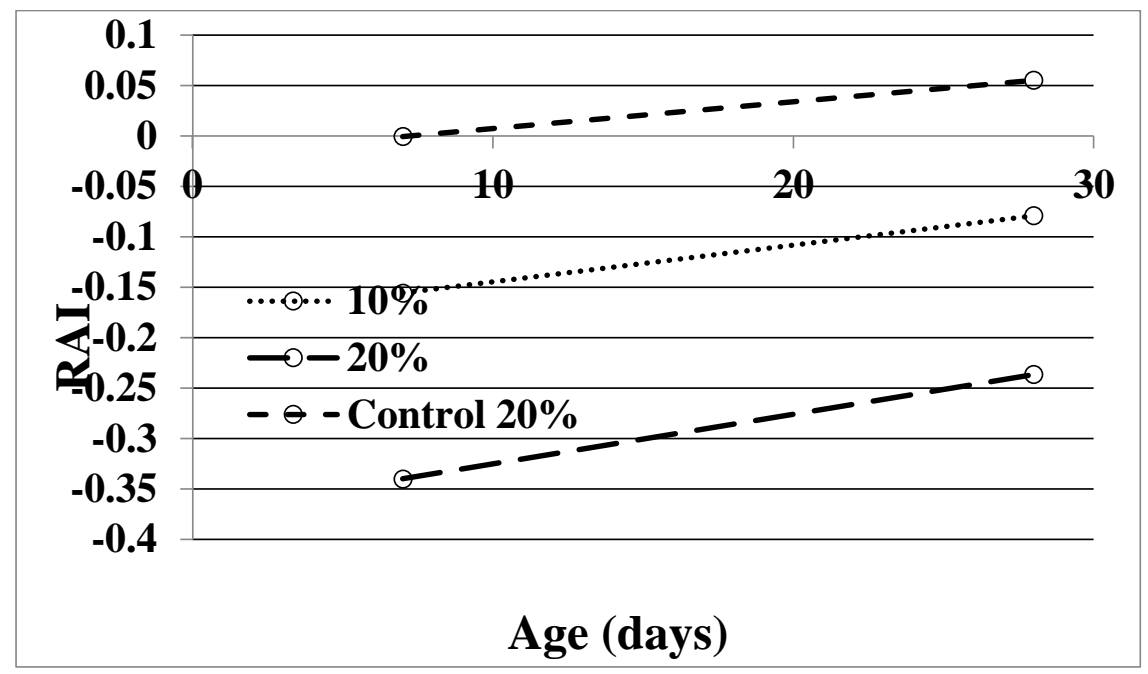

Figure 7. RAI as a function of age and BA as cement replacement

\section{Sand replacement}

Figure 8 shows the results of the compressive strength as a function of age and BA as the sand replacement. With an increased replacement, the compressive strength decreases, which is due to the necessity of additional water (which is required to have the same workability) and the replacement of a natural aggregate by a weaker one. 


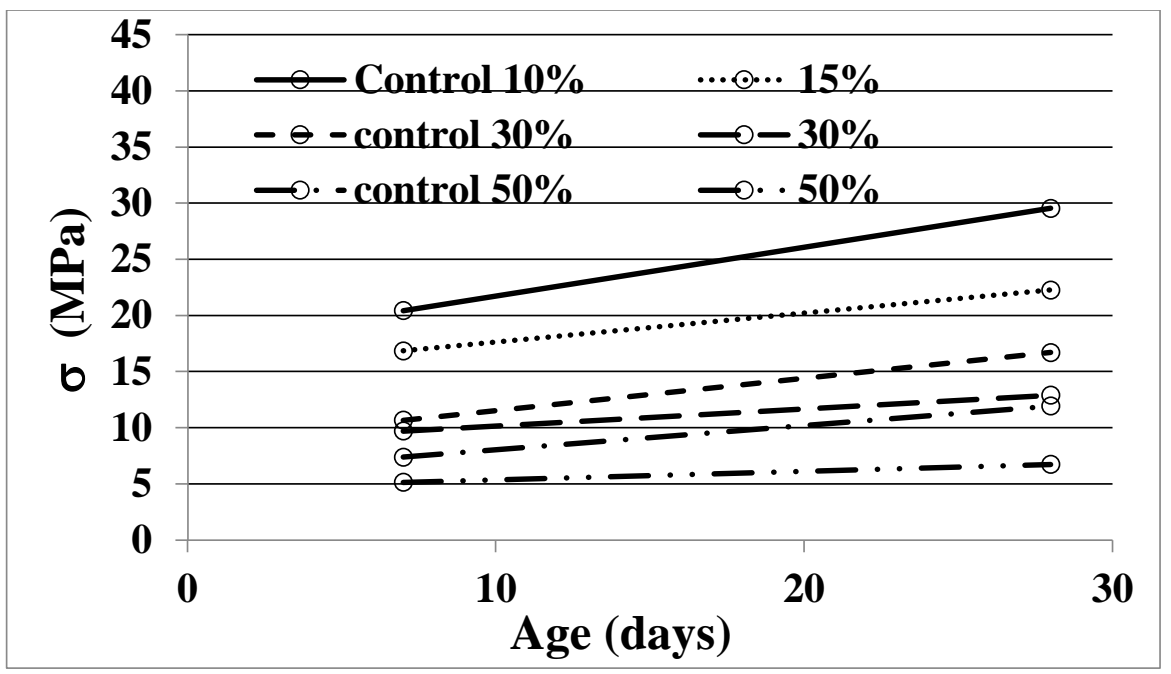

Figure 8. Compressive strength of concrete as a function of age and BA as the sand replacement

Figure 9 shows the results as a function of age and replacement. At 28 days, the $15 \%$ and $30 \%$ BA mixes are higher than $75 \%$ of the control, thus, they can be used. The optimum is located at $30 \%$ of the replacement in relation to its control. At 28 days, the normalized stress becomes smaller than at 7 days; this indicates a problem with the durability of this replacement. As a result, the replacement of the sand by the BA of the same size is not an effective solution.

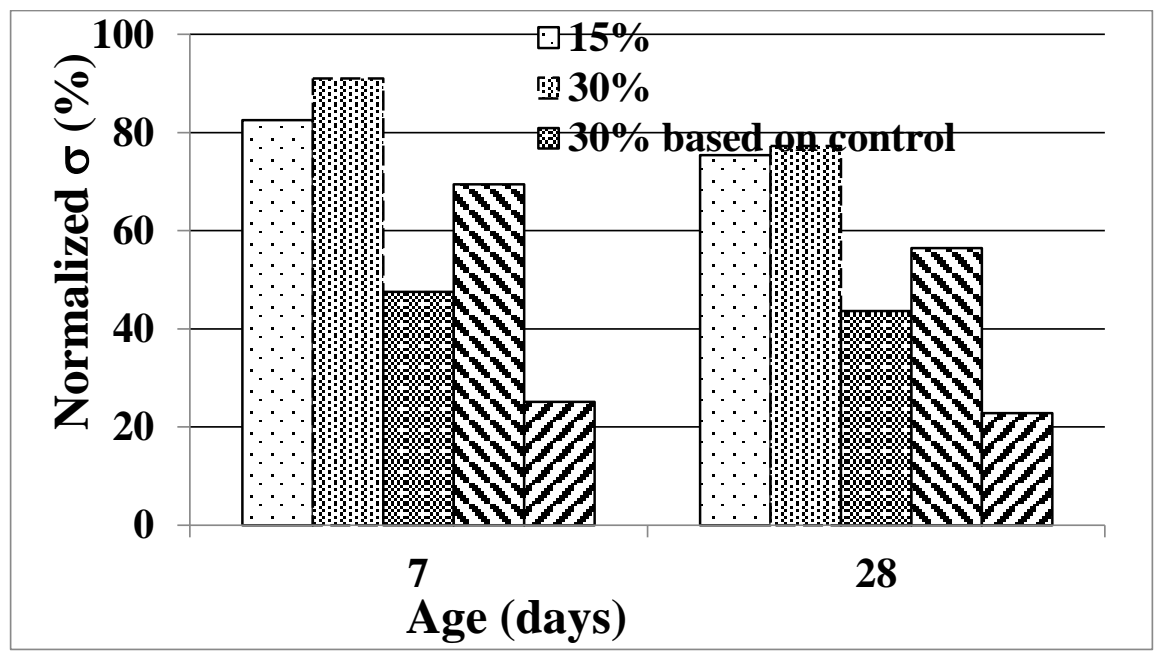

Figure 9. Relative compressive strength of concrete as a function of age and BA as the sand replacement

\section{Fine, medium, and coarse aggregates' replacement}

Figure 10 presents the results of the compressive strength as a function of age and replacement, where three replacements were conducted: BA replaced the fine aggregate (10\% FA); medium aggregate (10\% MA); and coarse aggregate (10\% CA). At 7 days, the $10 \%$ MA mix had a higher compressive strength than the control; nonetheless, at 28 days, its compressive strength became smaller but extremely close to the control. At 7 days, the fine and coarse aggregates' replacement had the same value; and then at 28 days, the CA developed a higher compressive strength than the FA. In order to obtain an in-depth understanding of these results, the normalized stress would be extremely helpful. 


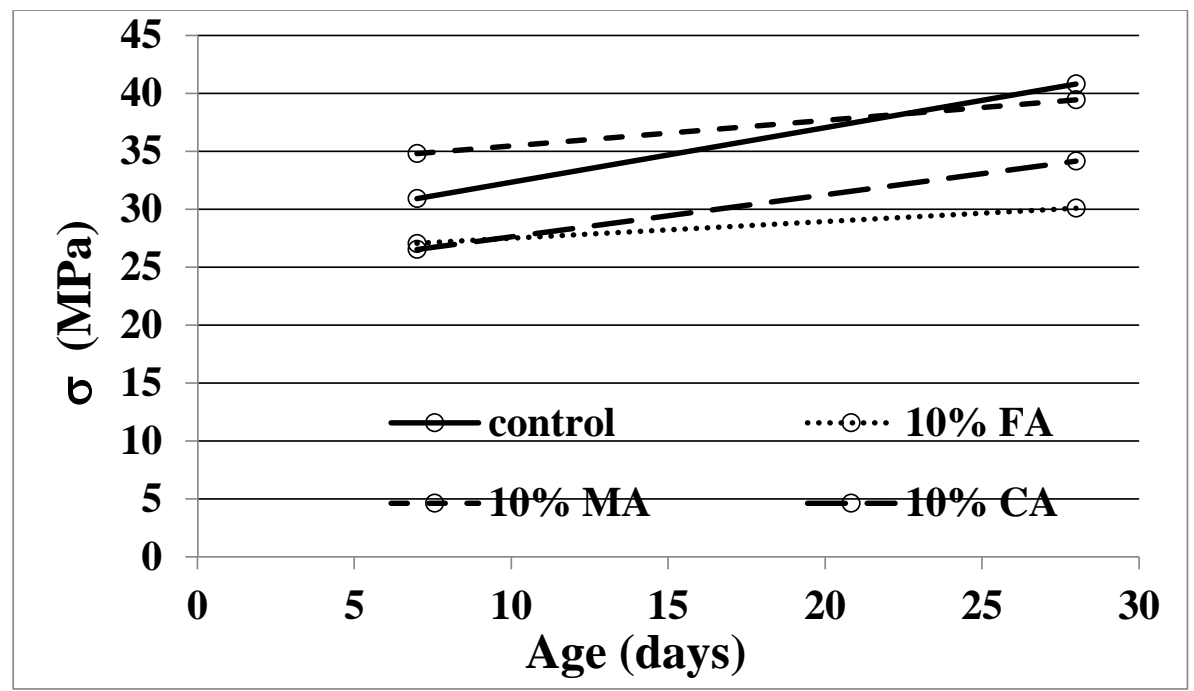

Figure 10. Compressive strength of concrete as a function of age and BA as an aggregate replacement

According to the calculation of the normalized stress, Fig. 11 demonstrates that at 28 days, the normalized values become smaller than at 7 days. Only the CA mix has an extremely small variation. Despite this decrease, it is still higher than $75 \%$ of the control stress.

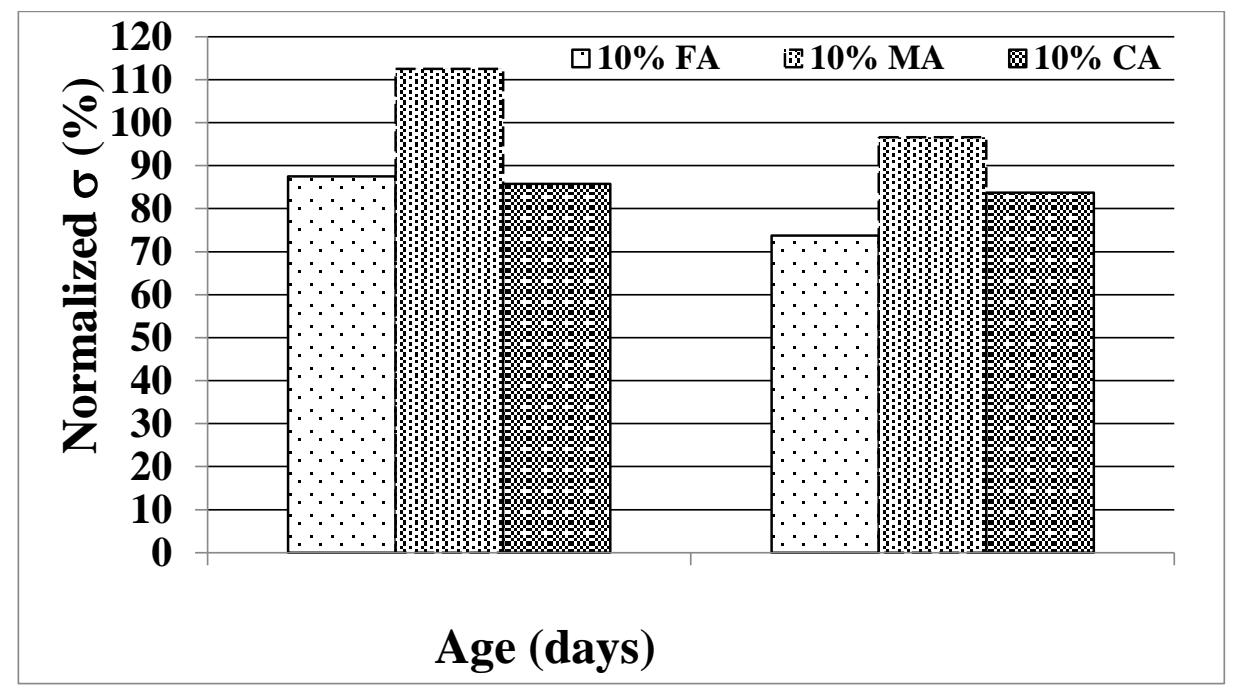

Figure 11. Relative compressive strength of concrete as a function of age and BA as an aggregate replacement

\section{CONCLUSION}

From the aforementioned investigations, the following conclusions were obtained:

1. Free water represents approximately $85 \%$ of organic domestic waste; this is due to the nature of the waste which is generally composed of vegetables.

2. After incineration, the BA represents less than $5 \%$ of the total mass of the waste.

3. The BA's chemical composition is extremely close to that of cement.

4. The optimum compressive strength of the cement replacement was $10 \%$.

5. The BA powder had a pozzolanic reaction which was proved by the fact that: the normalized compressive strength at 28 days was higher than at 7 days; the RAI for the pozzolanic reaction was positive according to the calculation.

6. The optimum compressive strength for the sand replacement was $30 \%$ and higher than $75 \%$ of the control. 
7. The medium aggregate BA replacement had the maximum compressive strength; it was higher than the control at 7 days and higher than $95 \%$ at 28 days.

8. The sand, fine and medium aggregates had a normalized compressive strength at 28 days, lower than at 7 days. This was due to the higher water absorption of the aggregate, which had a weaker interfacial transition zone between the cement paste and the aggregate.

\section{Data availability statement}

All data, models and code generated or used during the study appear in the submitted article.

\section{ACKNOWLEDGMENTS}

To my wife Rana who was my physical and moral support during my sceintifics research.

\section{REFERENCES}

Abbà, A., Collivignarelli, M.C., Sorlini, S. and Bruggi, M. 2014. "On the Reliability of Reusing Bottom Ash from Municipal Solid Waste Incineration as Aggregate in Concrete," Compos. B Eng. 58: 502-509. https://doi.org/10.1016/j.compositesb.2013.11.008.

Abdullah, M., Jin, T., Kadir, A., Tugui, C. and Sandu, A. (2017). "Use of Incineration Solid Waste Bottom Ash as Cement Mixture in Cement Production International Conference on Innovative Research - ICIR EUROINVENT.” IOP Publishing IOP Conf. vol. 2017.

Abu el Qomboz, Y. and Habil, I. (2000). Solid Waste Management in Gaza Strip Problems and Solutions. Gaza, Palestine: Islamic University of Gaza.

Aggarwal, Y. and Siddique, R. 2014. "Microstructure and Properties of Concrete Using Bottom Ash and Waste Foundry Sand as Partial Replacement of Fine Aggregates," Constr. Build. Mater. 54: 210-223. https://doi.org/10.1016/j.conbuildmat.2013.12.051.

Alhassan, H. and Tanko, A. 2012. "Characterization of Solid Waste Incinerator Bottom Ash and the Potential for Its Use,” Int. J. Eng. Res. Appl. (IJERA) 2: 516-522.

An, J., Kim, J. and Nam, B.H. 2017. "Investigation on Impacts of Municipal Solid Waste Incineration Bottom Ash on Cement Hydration,” ACI Mater. J. 114(5): 701-711. https://doi.org/10.14359/51689712.

ASTM C642-13. (2013). "Standard Test Method for Density, Absorption, and Voids in Hardened Concrete". www.astm.org. West Conshohocken, PA: ASTM International.

ASTM, C. (2018). C39M-18, Standard Test Method for Compressive Strength of Cylindrical Concrete Specimens. www.astm.org. West Conshohocken, PA: ASTM International.

ASTM C136. (2014). C136M-14. West Conshohocken, PA: Standard Test Method for Sieve Analysis of Fine and Coarse Aggregates, ASTM International.

ASTM C143. (2000). C143M-00, Standard Test Method for Slump of Hydraulic Cement Concrete. www.astm.org. West Conshohocken, PA: ASTM International.

ASTM C192. (2016). C192M-16a, Standard Practice for Making and Curing Concrete Test Specimens in the Laboratory. www.astm.org. West Conshohocken, PA: ASTM International.

Chen, C., Habert, G., Bouzidi, Y. and Jullien, A. 2010. "Environmental Impact of Cement Production: Detail of the Different Processes and Cement Plant Variability Evaluation," J. Clean. Prod. 18: 478.e485. https://doi.org/10.1016/j.jclepro.2009.12. 014.

Elaqra, H. 2014. "Valorization of Recycled Aggregate in Concrete and Mortar, Part A: Size Effect and Microstructure Changes on Mechanical Behavior, Palestine University”. Journal 7: 30-51. 
Elaqra, H. (2015). Valorization of Recycled Aggregate in Concrete and Mortar, Part B: Using Recycled Fine Aggregate as Replacement for Natural Aggregates in Mortar and as Replacement of Cement, Islamic University of Gaza, February 2015 Vol. 23(1),26-37.

Elaqra, H. (2019). Effect of the Use of Autoclave on Mechanical Properties of the Bio-Construction Materials Vol. 27(1),26-33. Islamic University of Gaza.

Elaqra, H., Naim, A. and Hussein, M. 2019. "Study on the Utilization of Local Waste as a Construction Aggregates for the Production of Concrete Blocks, Asian,” J. Eng. Technol. 07 (ISSN: $2321-2462)-(01$, Febr.).

Elaqra, H. and Rustom, R. 2018. "Effect of Using Glass Powder as Cement Replacement on Rheological Properties of Cement Paste," Constr. Build. Mater. 179: 326-335. https://doi.org/10.1016/j.conbuildmat.2018.05.263.

Huang, Y., Chen, J., Shi, Sh., Li, B., Mo, J. and Tang, Q. 2020. "Mechanical Properties of Municipal Solid Waste Incinerator (MSWI) Bottom Ash as Alternatives of Subgrade Materials," Adv. Civ. Eng. 2020: 1-11. https://doi.org/10.11s55/2020/9254516.

IEA, Cement production, 2010-2018, IEA, Paris https:/www.iea.org/data-and-statistics/charts/cementproduction-2010-2018

Kaza, S., Yao, L., Bhada-Tata, P. and F. Van Woerden. (2018). What a waste 2.0 a Global Snapshot of Solid Waste Management to vol. 2050 (urban development series, World Bank group).

Keppert, M. "Pavlík1 Z.." Černý R. Reiterman P. 2012, Properties of Concrete with Municipal Solid Waste Incinerator Bottom, A. and I. Coimbatore. “Conferences IPCSIT vol. 28." Singapore: ACSIT Press.

Li, X., Lv, Y., Ma, B., Chen, Q., Yin, X. and Jian, S. 2012. "Utilization of Municipal Solid Waste Incineration Bottom Ash in Blended Cement," J. Clean. Prod. 32: 96-100. https://doi.org/10.1016/j.jclepro.2012.03.038.

Lynn, C.J., R.K. Dhir OBE and Ghataora, G.S. 2016. "Municipal Incinerated Bottom Ash Characteristics and Potential for Use as Aggregate in Concrete," Constr. Build. Mater. 127: 504-517. https://doi.org/10.1016/j.conbuildmat.2016.09.132.

Maqadmh, A.R., Alfarra, M. and Alnahhal, M. Utilization of solid waste as a construction material. Unpublished Master Thesis. Gaza: The Islamic university. (2015).

Pu, X. (2004). Ultra-High Strength High Performance Concrete, Book, Chongqing University Press.

Rémond, S., Pimienta, P. and Bentz, D. 2002. "Effects of the Incorporation of Municipal Solid Waste Incineration Fly Ash in Cement Pastes and Mortars. I - Experimental Study Article in," Cem. Concr. Res. February 2002.

Siddique, R. 2010. "Use of Municipal Solid Waste Ash in Concrete," Resour. Conserv. Recycl. 55(2): 83-91. https://doi.org/10.1016/j.resconrec.2010.10.003.

ASTM D4691-17. (2017). Standard Practice for Measuring Elements in Water by Flame Atomic Absorption Spectrophotometry. West Conshohocken, PA: ASTM International.

Tam, V., Tam, C. and Wang, Y. 2007. "Optimization on Proportion for Recycled Aggregate in Concrete Using Tow-Stag Mixing Approach,” Constr. Build. Mater. 21: 19281939.

Tam, V.W.Y., Gao, X.F. and Tam, C.M. 2005. "Microstructural Analysis of Recycled Aggregate Concrete Produced from Two-Stage Mixing Approach," Cem. Concr. Res. 35(6): 1195-1203. https://doi.org/10.1016/j.cemconres.2004.10.025.

Tam, V.W.Y. and Tam, C.M. 2006. "A Review on the Viable Technology for Construction Waste Recycling," Resour. Conserv. Recy. 47(3): 209-221. https://doi.org/10.1016/j.resconrec.2005.12.002. 
Tam, V.W.Y. and Tam, C.M. 2007. "Crushed Aggregate Production from Centralized Combined and Individual Waste Sources in Hong Kong," Constr. Build. Mater. 21(4): 879-886. https://doi.org/10.1016/j.conbuildmat.2005.12.016.

Tang, P., Florea, M., Spiesz, P. and Brouwers, J. (2014). “The Application of Treated Bottom Ash in Mortar as Cement Replacement, EurAsia Waste Management Symposium, 28-30April 2014, YTU” Congress Center, İstanbul/Türkiye vol. 2010.

Van der Wegen, G., U. Hofstra and J. Speerstra. 2013. "Upgraded MSWI Bottom Ash as Aggregate in Concrete," Waste Biomass Valorization 4(4): 737-743. https://doi.org/10.1007/s12649-013-9255-6.

Whittaker, M., Taylor, R., Li, Q., Li, S. and Black, L. (2009). "The Behaviour of Finely Ground Bottom Ash in Portland Cement." Proceedings of the 29th Cement and Concrete Science Conference, Leeds, UK. Leeds, UK: White Rose Research Online. 